\title{
PLASMA TRACE ELEMENT STATUS IN BETA-THALASSEMIA TRAIT PATIENTS
}

\author{
PRABHAKARAN N, SUDHA K*, RESHMA K, DURGARAO Y
}

Department of Biochemistry, Kasturba Medical College, Mangalore, Manipal Academy of Higher Education, Manipal, Karnataka, India. Email: sudha.k@manipal.edu

Received: 04 August 2018, Revised and Accepted: 24 September 2018

ABSTRACT

Objective: The study aims to evaluate the plasma trace element status in beta-thalassemia trait (BTT) patients and demonstrate the correlation between trace elements and hemoglobin (Hb)-A1, HbA2, and $\mathrm{HbF}$.

Methods: The study population consisted of 20 normal individuals and 40 patients with BTT aged between 25 and 55 years of both the sex. Hemoglobin variant analysis was performed in blood samples using cation exchange high-performance liquid chromatography. Patients were labeled as beta-thalassemia trait only if they had $\mathrm{HbA} 2>3.5 \%$ or $\mathrm{HbF}>2.0 \%$. Plasma zinc was estimated by atomic absorption spectrometry, copper by bathocuproine disulfonate method, and iron by ferrozine method spectrophotometrically. Data were analyzed statistically by Student's $t$-test and Pearson's correlation using software SPSS version 20. $\mathrm{p}<0.05$ was considered statistically significant.

Results: Plasma zinc and copper decreased significantly in BTT patients compared to healthy controls. There was an apparent decrease in plasma iron in these patients. Degree of decline in zinc $(\mathrm{p}<0.001)$ was much greater than that of copper $(\mathrm{p}<0.04)$. Moreover, there was significant elevation of copper-zinc ratio and iron-zinc ratio $(\mathrm{p}<0.001)$ in BTT patients compared to controls. Both HbA1 and HbA2 correlated positively with both copper and iron. Interestingly, $\mathrm{HbF}$ showed negative correlation with all the three trace elements in BTT patients.

Conclusion: The study highlights marked deficiency of plasma trace elements, hence, the need for periodic assessment and prompt administration of these micronutrients to reduce the complications in BTT patients. Further, ratios are more valuable markers in the determination of trace element status than individual elements.

Keywords: Beta-thalassemia trait, Copper, Iron, Zinc, Trace elements.

(C) 2019 The Authors. Published by Innovare Academic Sciences Pvt Ltd. This is an open access article under the CC BY license (http://creativecommons. org/licenses/by/4. 0/) DOI: http://dx.doi.org/10.22159/ajpcr.2019.v12i1.28922

\section{INTRODUCTION}

Beta-thalassemia trait (BTT) is the most common single-gene inherited hemoglobinopathy in India with no gender discrimination. Among all the health problems in India, though the burden of hemoglobinopathies is significant, little attention has been given compared to malnutrition and other communicable diseases [1]. In beta-thalassemia, there is reduced production of beta-globin chains and increased synthesis of alpha and gamma chains. Increased alpha chains make the developing erythrocytes more fragile, leading to ineffective erythropoiesis, early damage, and anemia. Some of the patients may exhibit other symptoms such as impaired immune status, osteoporosis, and infections [2]. Deficiency of various micronutrients such as minerals and vitamins adds to the complications in these patients. Trace elements, namely iron, copper, and zinc, are required for heme biosynthesis. Copper plays a key role in several enzymatic reactions in RBC and its deficiency interferes with iron transport and therefore heme synthesis. Zinc is another trace element that is essential for cell-mediated immunity, activation of ALA dehydratase, and general growth [3]. Most of the trace element studies have been done on beta-thalassemia major patients and data are scarce on trait patients. Hence, our study aims to evaluate the plasma trace elements and demonstrate the correlation between trace elements and $\mathrm{HbA} 1, \mathrm{HbA} 2$, and $\mathrm{HbF}$ in BTT patients.

\section{METHODS}

The study population consisted of 20 normal individuals and 40 patients with BTT aged between 25 and 55 years of both the sex. Random blood samples were collected in EDTA vacutainers and centrifuged at $3000 \mathrm{~g}$ for $10 \mathrm{~min}$, plasma separated was used for the estimation of zinc by atomic absorption spectrometry and copper by bathocuproine disulfonate method where cuprous ions react with bathocuproine disulfonate to give a red-colored product [4]. Plasma iron was estimated by ferrozine method, in which ferrous ions formed by reduction using ascorbate combines with ferrozine to produce colored complex which is then measured spectrophotometrically [5]. Hemoglobin variant analysis was performed in blood samples using cation exchange high-performance liquid chromatography. Patients were labeled as beta-thalassemia trait only if they had $\mathrm{HbA} 2>3.5 \%$ or $\mathrm{HbF}>2.0 \%$. Patients with anemia $(\mathrm{Hb}<14.0 \mathrm{~g} \%$ in males and $<12.0 \mathrm{~g} \%$ in females) with no evidence of "nutritional deficiency," renal or hepatic derangement, or chronic infection were considered for the study. None of the participants had taken mineral supplements before blood sampling. The study was approved by the institutional ethical committee and informed consent was taken from all the patients. Data were analyzed statistically by Student's $t$-test and Pearson's correlation using software SPSS version 20. $\mathrm{p}<0.05$ was considered statistically significant.

\section{RESULTS}

Hemoglobin A1 level was significantly lower with concomitant increase in $\mathrm{HbA} 2$ and $\mathrm{HbF}$ in BTT patients compared to normal individuals (Table 1). There was an apparent decrease in iron values in BTT patients and the decrease in zinc and copper in BTT patients were statistically significant compared to healthy individuals. Degree of decline in zinc level $(\mathrm{p}<0.001)$ was much greater than that of copper $(p<0.04)$ (Table 2). Further, there was a marked elevation in iron-zinc ratio and copper-zinc ratio $(\mathrm{p}<0.001)$ in BTT compared to controls. There was an insignificant negative correlation between zinc and different hemoglobins. Both $\mathrm{HbA} 1$ and $\mathrm{HbA} 2$ correlated positively with both copper and iron. Interestingly, $\mathrm{HbF}$ showed negative correlation with all the three trace elements in BTT patients (Table 3). 
Table 1: Comparison of hemoglobin levels in BTT patients and normal controls

\begin{tabular}{llll}
\hline Parameter & Normal(n=20) & BTT(n=40) & p value \\
\hline HbA1 (g \%) & $96.36 \pm 1.3$ & $90.90 \pm 2.28$ & $<0.001$ \\
HbA2 (g \%) & $2.94 \pm 0.24$ & $5.27 \pm 0.24$ & $<0.001$ \\
HbF (g \%) & $0.73 \pm 0.49$ & $1.49 \pm 1.26$ & 0.081 \\
\hline
\end{tabular}

n: Number of samples. BTT: Beta-thalassemia trait, Hb: Hemoglobin

Table 2: Comparison of plasma trace elements in normal and BTT

\begin{tabular}{llll}
\hline Parameter & Normal(n=20) & BTT(n=40) & p value \\
\hline Copper $(\mu \mathrm{g} / \mathrm{dl})$ & $96.41 \pm 13.66$ & $85.66 \pm 14.77$ & 0.04 \\
Zinc $(\mu \mathrm{g} / \mathrm{dl})$ & $83 \pm 5$ & $40 \pm 9$ & $<0.001$ \\
Copper: $\mathrm{zinc}$ & $1.16 \pm 0.21$ & $2.34 \pm 0.84$ & $<0.001$ \\
Iron $(\mu \mathrm{g} / \mathrm{dl})$ & $74.07 \pm 10.6$ & $62.64 \pm 28.8$ & 0.26 \\
Iron: copper & $0.77 \pm 0.13$ & $0.72 \pm 0.05$ & 0.17 \\
Iron: zinc & $0.89 \pm 0.11$ & $1.56 \pm 0.27$ & 0.001 \\
\hline
\end{tabular}

n: Number of samples. BTT: Beta-thalassemia trait

\section{Table 3: Correlation of trace elements with hemoglobins in BTT}

\begin{tabular}{lllllll}
\hline & $\mathbf{C u}$ & & $\mathbf{Z n}$ & & $\mathbf{F e}$ & \\
\cline { 2 - 7 } & $\mathbf{r}$ & $\mathbf{p}$ & $\mathbf{r}$ & $\mathbf{p}$ & $\mathbf{r}$ & $\mathbf{p}$ \\
\hline HbA1 & 0.18 & 0.29 & -0.45 & 0.79 & 0.68 & 0.09 \\
HbA2 & 0.05 & 0.73 & -0.01 & 0.95 & 0.06 & 0.88 \\
HbF & -0.20 & 0.43 & -0.84 & 0.75 & -0.76 & 0.13 \\
\hline
\end{tabular}

BTT: Beta-thalassemia trait, Hb: Hemoglobin

\section{DISCUSSION}

Trace elements play a key role in metabolism within erythrocytes by participating in heme biosynthesis and other enzymatic reactions. BTT is a common heterozygous hemoglobinopathy characterized by hypochromia, microcytosis, and low-grade hemolysis [6]. Deficiency of trace elements like zinc is implicated in immune dysfunction. Moreover, impaired immune function is one of the salient features of BTT. Thus, alterations in these essential minerals seem to be related to different clinical complications associated with BTT.

The present study demonstrated a significant decrease in both copper and zinc in plasma of BTT patients compared to healthy controls. In accordance with our study, thalassemia major patients on iron chelation therapy and Jordanian thalassemia patients also exhibited decreased plasma copper and zinc $[7,8]$. However, thalassemic natives of Iran showed high copper but low plasma zinc [9]. In contrast, plasma copper remained normal in thalassemia major children but high in adult patients $[10,11]$. Increase in copper level has been attributed to recurrent infections in thalassemia major patients. Decreased plasma zinc in adult thalassemia major patients was also true for thalassemia minor patients as noted in our results. Decrease in plasma zinc may be due to increased excretion of zinc in urine released from hemolyzed red cells and due to malabsorption. Deficiency of zinc both in erythrocytes and plasma was a common feature of other hemoglobinopathies such as sickle cell disease and $\mathrm{Hb}$ E $[12,13]$. Further, copper and zinc deficiency may lead to a significant decline in erythrocyte membrane SOD, leading to increased oxidative stress and decreased RBC survival time [14]. Sickle cell anemia patients treated with zinc showed improvement both in skeletal growth and immune status [15]. Interestingly, zinc correlated negatively with all types of hemoglobins. Further, BTT patients exhibited marked elevation in copper-zinc ratio than individual elements in the present study, highlighting the fact that this ratio may be a more valuable indicator of imbalance in the microelement status in hemoglobinopathies [9]. Decrease in plasma iron in BTT patients as observed in the present study may be due to low ceruloplasmin that interferes in iron transport and utilization. Moreover, Babu et al. observed significant variation in complete hemogram in BTT patients compared to healthy individuals justifying our findings [16]. Ironzinc ratio doubled in BTT patients compared to normal signifying the importance of ratios in assessing the trace element status in these patients. In RBC, free iron is most likely redox active element that leads to the production of hydroxyl radical which initiates membrane lipid peroxidation and protein oxidation thereby hemolysis. On aerobic incubation of RBCs, release of free iron was greater in BTT patients than controls [17]. High levels of $\mathrm{HbF}$ in BTT patients correlated with iron release, suggesting that persistence of $\mathrm{HbF}$ favors iron release and excess alpha chains act as prooxidants [18]. Moreover, trace elements (iron and copper) correlated positively with $\mathrm{Hbs}$ (A1 and A2) and a negatively with $\mathrm{HbF}$ in BTT patients. On the contrary, earlier reports showed no correlation between the iron state and the hemoglobin levels in beta-thalassemia trait subjects [19].

The study highlights marked deficiency of plasma trace elements, hence, the need for periodic assessment and prompt administration of these micronutrients to reduce the complications in BTT patients.

\section{AUTHORS' CONTRIBUTION}

Prabhakaran: Biochemical analysis, Dr. Sudha K: Study design and manuscript preparation, Dr. Reshma K: Manuscript revision, and Mr.Durgarao: Statistical analysis.

\section{CONFLICTS OF INTEREST}

There are no conflicts of interest among the authors.

\section{REFERENCES}

1. Grow K, Vashist M, Abrol P, Ritu Y. Beta thalassemia in India: Current status and the challenges ahead. Int J Pharm Pharm Sci 2014;6:28-33.

2. Shamshirsaz AA, Bekheirnia MR, Kamgar M. Metabolic and endocrinologic complications in beta-thalassemia major: A multicenter study in Tehran. BMC Endocrine Disorders 2003;3:658-63.

3. Prasad AS. Zinc in human health: Effect of zinc on immune cells. Mol Med 2008; 14:353-7.

4. Prakash M, Shetty J. A modified spectrophotometric micro method to determine serum copper. Asian J Biochem 2008;3:38-42.

5. Eva H, Suderman W. An accurate spectrophotometric method for serum iron and iron binding capacity without deproteinization or centrifugation. Ann Clin Lab Sci 1974;4:87-95.

6. Kalman S, Atay A, Sakallioglu O, Ozqurtas T, Gok F, Ismail K, et al. Renal tubular function in children with beta thalassemia minor. Nephrology 2005;10:427-9.

7. Kamal M, Talal A, Moussa B, Hamzeh N. Copper and zinc status in Jordanian patients with $\beta$-thalassemia major treated with deferoxamine. Res J Biol Sci 2009;4:566-72.

8. Mansi KI. Status of thyroid function and iron overload in adolescents and young adults with beta- thalassemia major treated with deferoxamine in Jordan. Proc World Acad Sci Eng Technol 2009;58:658-63.

9. Dangi CB, Manpreet K, Singh M. Copper and zinc quotient in haemoglobinopathies. Biomed Pharmacol J 2011;4:165-73.

10. Mahyar A, Ayazi P, Pahlevan AA, Mojabi H, Sehhat MR, Javadi A. Zinc and copper status in children with beta-thalassemia major. Iran J Pediatr 2010;20:297-302.

11. Al-Samarrai AH, Adaay MH, Al-Tikriti KA, Al-Anzy MM. Evaluation of some essential element levels in thalassemia major patients in Mosul district, Iraq. Saudi Med J 2008;29:94-7.

12. Ramdas M, Manpreet K, Ahmed A, Dangi CB. Trace elements ratio in patients of haemoglobinopathies. Int J Curr Microbiol App Sci 2014;3:81-92.

13. Suthipark KU, Likidillid A, Fucharoen S, Pootrakul P, Shumnumsirivath D, Ong-ajyooth S, et al. Red cell and plasma calcium, copper and zinc in beta thalassemia/hemoglobin E. Southeast Asian J Trop Med Public Health 1991;22:171-5.

14. Filiz S, Gulyuz O, Sabri K, Deniz E, Alev H. Oxidant and antioxidant status in beta thalassemia major patients. J Ankara Univ Fac Med 2005;58:34-8.

15. Bao B, Prasad AS, Beck FW, Snell D, Suneja A, Sarkar FH, et al. Zinc supplementation decreases oxidative stress, incidence of infection, and generation of inflammatory cytokines in sickle cell disease patients. Transl Res 2008;152:67-80. 
16. Babu S, Ashwini SS, Manjula S. Premarital screening of beta thalassemia trait in Dakshina Kannada population of Karnataka. Int $\mathbf{J}$ Pharm Pharm Sci 2016;9:268-72.

17. Ciccoli L, Signorini C, Scarano C, Rossi V, Bambagioni S, Ferrali M, et al. Iron release in erythrocytes from patients with beta-thalassemia. Free Radic Res 1999;30:407-13
18. Comporti M, Signorini C, Buonocore G, Ciccoli L. Iron release, oxidative stress and erythrocyte ageing. Free Radic Biol Med 2002;32:568-6.

19. da Fonseca SF, Kimura EY, Kerbauy J. Assessment of iron status in individuals with heterozygotic beta-thalassemia. Rev Assoc Med Bras 1995;41:203-6. 